\title{
Evidence for processing of compact insoluble thyroglobulin globules in relation with follicular cell functional activity in the human and the mouse thyroid
}

\author{
A-C Gérard, J-F Denef, I M Colin and M-F van den Hove ${ }^{1}$ \\ Histology and ${ }^{1}$ Cell Biology Units, Christian de Duve Institute of Cellular Pathology and Université Catholique de Louvain, Medical School, \\ Brussels, Belgium \\ (Correspondence should be addressed to M-F van den Hove, Cell Biology Unit, ICP, Université Catholique de Louvain, Medical School, UCL-7541, \\ 75 Av. Hippocrate, B-1200 Brussels, Belgium; Email: vandenhove@cell.ucl.ac.be)
}

\begin{abstract}
Objective: Thyroglobulin ( $\mathrm{Tg})$ is stored within the follicular lumen mainly in a soluble form, but globules made of insoluble multimers are also present and considered to be a mechanism to store prohormone at high concentration. We investigated the immunohistochemical properties of these intrafollicular globules and their possible processing by thyroid cells upon stimulation in the human and in the mouse.

Design: Human thyroids (normal, Graves' disease and hot adenomas) and thyroids from old ICR mice without or with goitrogenic treatment were processed for light microscopy.

Methods: Immunohistochemistry for Tg with a polyclonal antibody and two monoclonal antibodies, one specific for thyroxine-rich-iodinated $\mathrm{Tg}$ and the other recognizing $\mathrm{Tg}$ independently of its iodine level, staining with periodic-acid-schiff, and binding of lectins specific for mannose and sialic acid were performed on all tissue sections. Intrafollicular globules were quantified, with distinction between 'active' or 'hot' and 'hypofunctioning' or 'cold' follicles.

Results: In normal human and old mouse thyroids, the intrafollicular globules were strongly stained with PAS, but negative for the three anti-Tg antibodies and the two lectin-binding assays, while the surrounding soluble Tg was positive. In normal human tissue, globules were more frequent in 'hypofunctioning' than in 'active' follicles. They were exceptional in Graves' disease and hot adenomas. In old mice, Tg globules were more frequent in 'cold' than in 'hot' follicles. Along with the goitrogen treatment, they became fewer, fragmented and more often present in follicles with a 'hot' aspect. Conclusions: Upon TSH stimulation, thyrocytes become able to process colloid globules suggesting that this stock of Tg can be used in vivo for thyroid hormone synthesis.
\end{abstract}

European Journal of Endocrinology 150 73-80

\section{Introduction}

Thyroglobulin $(\mathrm{Tg})$ is an iodinated glycoprotein that is required for thyroid hormone formation. The prohormone $\mathrm{Tg}$ is stored as colloid within the follicular lumen. As its concentration increases, diffusion into the colloid slows down and iodination and hormone synthesis are affected (1). Colloid is compartmentalized with a higher turnover at the periphery than in the center (2). Tg iodination takes place extracellularly at the apical pole of the thyrocytes and proceeds in two steps: a rapid iodination of newly synthesized molecules and a delayed iodination of older molecules stored in the colloid. Only a few specific tyrosine residues are involved in the hormonogenesis and one thyroxine (T4)-forming site at a low degree of iodination is located at the N-terminal end of the molecule. Iodination acts on the $\mathrm{Tg}$ structure by increasing the formation of intermolecular disulfide bonds. This leads to the formation of soluble dimers, tri- and tetramers made of attached 19S molecules with the same ovoid shape, and the same degree of iodination, but with a higher sialic acid content (3). Tg also exists in a multimerized insoluble form which consists of covalently cross-linked 19S Tg molecules. Such colloid globules have been isolated from bovine and human thyroids, with differences in size and cross-linking nature $(4,5)$. Iodine content of isolated globules is high while hormones have not been detected $(4,6)$.

It has been suggested that $\mathrm{Tg}$ compaction is a mechanism to store the prohormone at high concentration $(4,5)$. A morphological heterogeneity in the colloid aspect along with the presence of intrafollicular globules has also been observed on fixed histological sections $(7,8)$. In the present study, we analyzed the immunohistochemical properties of the intrafollicular 
globules in two models: the human thyroid and the glands of old mice which are known to contain numerous hypoactive 'cold' follicles (9). To look at the possible processing of the colloid globules by thyroid cells, we compared hyperactive samples from Graves' goiter and from autonomous adenomas with normal human tissues. To analyze the processing steps leading to $\mathrm{Tg}$ globule vanishing, a thyrotropin (TSH)-induced iodoprive goiter was produced in old mice.

\section{Materials and methods}

\section{Human tissues}

Normal human thyroid tissue was obtained at necropsy. Thyroids samples from five patients with Graves' disease or autonomous 'hot' adenomas were selected from the tissue bank of the Department of Pathology. For cryosections, normal tissue was obtained from four patients undergoing surgery for multinodular goiter, after informed consent had been given.

\section{Animals and treatment}

Twenty-four 18- to 24-month-old ICR mice were divided into one control group and three other groups on an iodine-deficient diet (LID, corresponding to $0.1 \mu \mathrm{g}$ I/day; Animalabo, Brussels, Belgium), supplemented with $0.25 \%(\mathrm{w} / \mathrm{v})$ 6-n-propyl-2-thiouracyl (Sigma, St Louis, MO, USA) for 10, 22, or 34 days respectively, followed by LID alone for 2 days. Animals were fed a normal iodine diet $(1 \mu \mathrm{g} \mathrm{I} /$ day $)$ from birth until the onset of the treatment. Mice were maintained in accordance with the principles of laboratory animal care. Two 19- and 21-month-old C57 black mice were fed a normal iodine diet and injected with $30 \mu \mathrm{Ci}{ }^{125} \mathrm{I}$ (IMS 30; Amersham Bioscience, Roosendaal, The Netherlands) $4 \mathrm{~h}$ before they were killed.

\section{Microscopy}

Human samples were Bouin-fixed and paraffinembedded tissues. Serial sections $(5 \mu \mathrm{m}$ thick $)$ were stained with eosin-orange G (EOG) and periodic-acid-schiff (PAS) methods, or used for immunohistochemistry and lectin-binding analysis (see below). Tissues obtained from surgery were rapidly frozen in liquid nitrogen. Cryostat sections ( $5 \mu \mathrm{m}$ thick) were stained with hematoxylin-eosin (HE).

Old mice were anesthetized with pentothal and perfused through a cannula placed in the left ventricle under a pressure of $80 \mathrm{mmHg}$, first with saline for $1 \mathrm{~min}$ at $37^{\circ} \mathrm{C}$, and thereafter with paraformaldehyde (4\%) and dextran (3.5\%) in phosphate-buffered saline (PBS) buffer ( $\mathrm{pH}$ 7.4) for $4 \mathrm{~min}$. One thyroid lobe was carefully dissected and immediately fixed in Bouin-Allen solution, while the second lobe was left in situ. The perfusion was then prolonged with paraformaldehyde (2\%), glutaraldehyde $(2.5 \%)$ and dextran $(3.5 \%)$ in $100 \mathrm{mM}$ cacodylate buffer $(\mathrm{pH} 7.4)$ for $5 \mathrm{~min}$. The second lobe was fixed in $2.5 \%$ glutaraldehyde for $1.5 \mathrm{~h}$, rinsed in cacodylate buffer, and post-fixed in osmium tetroxide for $1 \mathrm{~h}$. After dehydration, the first lobe was embedded in paraffin, and serial $5 \mu \mathrm{m}$ thick sections were stained with EOG and PAS methods or used for immunohistochemistry and lectin-binding analysis. Autoradiographies were performed as previously described (10). The second lobe was embedded in LX112 resin (Ladd Research Industries, Burlington, VT, USA). Semi-thin sections (0.5 $\mu \mathrm{m}$ thick), stained with toluidine blue, were used to count the number of intrafollicular globules.

\section{Immunohistochemistry and lectin-binding analysis}

All procedures were performed at room temperature. Paraffin sections were dewaxed and rehydrated. Cryostat sections were quickly plunged into acetone. After washing with PBS containing $1 \%$ bovine serum albumin (BSA) (PBS-BSA) (BSA; ICN, Costa Mesa, CA, USA), sections were incubated with $1 \% \mathrm{H}_{2} \mathrm{O}_{2}$ for $20 \mathrm{~min}$, washed twice with PBS-BSA, and processed using three different antibodies raised against human $\mathrm{Tg}$ (hTg). The rabbit polyclonal antibody (not species specific) was used at 1:1500 for $3 \mathrm{~h}$ (Dako, Glostrup, Denmark). The two other mouse monoclonal antibodies (Mabs) were used at 1:4000, overnight (11). The A3 Mab (human specific) is directed against hTg without discrimination between the different iodine contents of $\mathrm{Tg}$, while the B1 Mab (reacting with human and mouse $\mathrm{Tg}$ ) specifically recognizes iodinated Tg containing $\mathrm{T} 4$ at the N-terminal hormonogenic site (Mabs were a gift from Dr J J M de Vijlder, Amsterdam). For antibody-antigen reaction revelation, a 1-h incubation with a second peroxidase-conjugated swine polyclonal anti-rabbit (Dako) or rat monoclonal antimouse antibodies was performed, followed by the diaminobenzidine tetrahydrochloride (Aldrich, Bornem, Belgium) $-\mathrm{H}_{2} \mathrm{O}_{2}$ peroxidase reaction. Sections were counterstained with Mayer's hematoxylin, rinsed, dehydrated and mounted in DPX medium (BDH, Poole, Dorset, UK). A3 Mab immunostaining was only performed on human sections. The first antibody was omitted in the controls. The specificity of the B1 Mab was checked after preincubation with iodinated or non-iodinated hTg.

For lectin-binding analysis, concanavalin A (ConA) was used to detect terminal $\alpha$-D-mannosyl residues, and Sambucus nigra agglutinin (SNA) to detect sialic acid bound in $\alpha_{2-6}$ to galactose. Paraffin sections of normal human and mice thyroids were washed with $10 \mathrm{mM}$ acetate buffer ( $\mathrm{pH}$ 6.0), $1 \mathrm{mM} \mathrm{CaCl}_{2}$, and $1 \mathrm{mM} \mathrm{MnCl}_{2}$ (ConA), or with $10 \mathrm{mM}$ Hepes buffer (pH 7.5) and $1 \mathrm{mM} \mathrm{CaCl} 2$ (SNA), and incubated for $30 \mathrm{~min}$ with $10 \mu \mathrm{g} / \mathrm{ml}$ ConA (Sigma-Aldrich, Bornem, 
Belgium), or for $1 \mathrm{~h}$ with $20 \mu \mathrm{g} / \mathrm{ml}$ SNA (USB, Cleveland, OH, USA), both biotin conjugated, in their respective buffer. After washes in Tris- $\mathrm{HCl}(\mathrm{pH} 7.0)$, lectin binding was revealed by alkaline phosphataseconjugated streptavidin (Roche-Diagnostics, Manheim, Germany), followed by Fast-red reaction after washes in Tris ( $\mathrm{pH}$ 8.2) (Roche-Diagnostics). Sections were counterstained and mounted in aquamount (BDH). In control sections, ConA was preincubated with $\alpha$-Dmannose (Sigma) and SNA with N-acetylneuraminoside-D-lactose (Sigma).

\section{Counting of follicles with globules}

For quantification in human tissues, Tg globules, considered as insoluble $\mathrm{Tg}$ multimers, were counted in 1000 follicles on EOG-stained sections at $\times 400$ magnification. Follicles were ranked into two classes according to the aspect of their epithelium which correlates with their functional status. 'Active' follicles were lined with a cubical or a cylindrical epithelium with round nuclei, while 'hypofunctioning' follicles were surrounded by flat epithelium and nuclei (12). Globules present in 'active' and 'hypofunctioning' follicles were counted separately.

To confirm the preferential location of globules within 'hypofunctioning' follicles, we analyzed their repartition in the thyroid of old mice which are known to develop hypofunctioning 'cold' follicles with aging $(9,13-15)$. Globules were counted separately in each type of follicles at $\times 400$ magnification on sections corresponding to one thyroid lobe. A differentiation was made between follicles with a unique central globule and those with multiple fragments with similar histochemical properties.

\section{Statistical analysis}

The statistical difference between both types of follicles in the same group, or between groups was tested by one-way analysis of variance and by Student's t-test. Differences were considered significant at $P<0.05$. Results are expressed as means \pm S.D., $n=5$.

\section{Results}

\section{Globules present in follicular lumen of human and old mouse thyroid react differently to anti-Tg antibodies and lectins than the surrounding soluble Tg}

In human follicles, we observed that the histochemical properties of globules differed from those of the surrounding soluble $\mathrm{Tg}$. On serial sections stained with EOG, the globules appeared either as a unique large and central corpuscle or as numerous, small, and dispersed structures floating in the follicular lumen; these were more strongly pink stained than the periphery of the colloid (not shown). A similar contrasted difference was observed with PAS staining (Fig. 1 A and B), indicating that the cross-linked Tg was glycosylated. In contrast, the globules were negative either with the polyclonal anti-Tg antibody (Fig. 1C and D), or with the two Mabs that are specific for T4-containing Tg (B1 Mab), and for Tg independently of its iodination level (A3 Mab, not shown). Staining of the soluble Tg persisted after preincubation of the B1 Mab with noniodinated hTg, while it disappeared after preincubation with iodinated hTg, confirming the antibody specificity (Fig. 1E and F).

In frozen sections, most of the soluble $\mathrm{Tg}$ was extracted during the immunostaining procedure, but globules remained in the follicular lumen, confirming their insolubility. Here again, the globules were HE and PAS positive (not shown), but not reactive to the polyclonal anti-Tg antibody (Fig. 1G), indicating that they were not just a fixation artifact.

Globules were totally negative for ConA binding and clearly less positive than soluble colloid for SNA binding (Fig. $1 \mathrm{H}$ and I).

In the thyroid of old mice, intrafollicular globules showed the same staining and immunological properties as in the human: they were PAS positive (not shown), but did not react with the B1 Mab (Fig. 1J), or with the polyclonal anti-Tg Ab (not shown). Globules were also negative in the ConA-binding test, in contrast with the positive surrounding Tg. They were mainly detected in 'cold' follicles, identified by the absence of radioiodine uptake on autoradiography (Fig. 1K).

\section{Globules were more frequently present in hypofunctioning follicles and were processed upon thyroid stimulation}

Quantification of $\mathrm{Tg}$ globules present in 'active' or 'hypofunctioning' follicles in human thyroids is

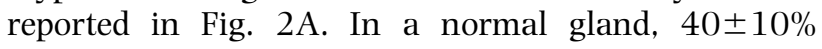
$(n=5)$ of the follicles showed a 'hypofunctioning' morphological aspect, half of them containing globules. In contrast, globules were only observed in $22 \%$ of the more frequent 'active' follicles.

In control old mice (Fig. 2B), $58 \pm 13 \%$ of the follicles were 'cold', with $45 \%$ of them containing globules. In contrast, only $8 \%$ of the 'hot' follicles contained globules. These results confirmed that multimers of $\mathrm{Tg}$ are more frequent in 'hypofunctioning' than in 'active' follicles.

We then analyzed the globule distribution in tissues from two human pathologies characterized by hyperactivity, Graves' disease and hot autonomous adenomas. As shown in Fig. 2A, these tissues contained mainly 'active' follicles. Globules were quite rare and distributed equally in both types of follicles. These results indicated that thyrocytes can make use of the colloid globules when they are stimulated. 

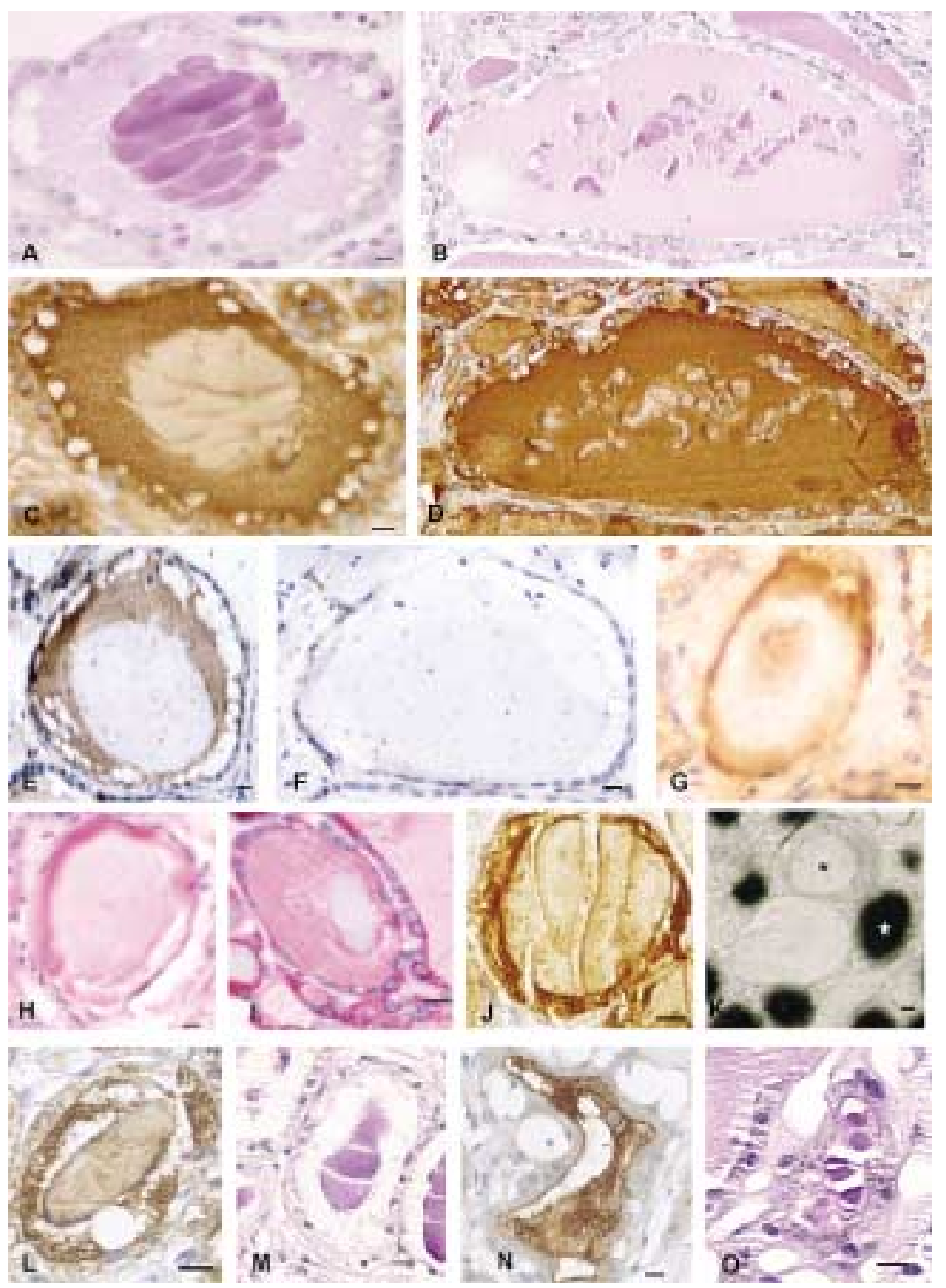

Figure 1 Intrafollicular globules are present in thyroids of normal humans $(A-I)$ and old ICR mice $(J-O)$. Scale bar $=10 \mu \mathrm{m}$. (A-D) Unique central globule and multiple small aggregates floating in the colloid in human normal thyroid: (A and B) PAS staining and ( $C$ and $D$ ) immunostaining with polyclonal anti-Tg antibody; serial sections. ( $E$ and $F$ ) Control of B1 Mab specificity: preincubation with (E) non-iodinated $\mathrm{hTg}$ or $(\mathrm{F})$ iodinated $\mathrm{hTg}$. (G) Globule on a cryostat section; immunostaining with polyclonal anti-Tg antibody. ( $\mathrm{H}$ and $\mathrm{I}$ ) Lectin binding: $(\mathrm{H})$ binding of SNA (sialic acid binding) and (I) binding of ConA (mannose binding). ( $\mathrm{J}$ ) Globule in a 'cold' follicle of a control old ICR mouse; immunostaining with B1 Mab. (K) Globule in a 'cold' follicle in an old C57 black mouse; autoradiography $4 \mathrm{~h}$ after ${ }^{125}$ I injection (black asterisk, 'cold' follicle; white asterisk, 'hot' follicle). ( $L$ and $\left.M\right)$ Globule in a 'hot' follicle of an old ICR mouse on goitrogen treatment for 24 days: (L) immunostaining with polyclonal anti-Tg antibody and (M) PAS staining. $(\mathrm{N}$ and $\mathrm{O}$ ) 'Hot' follicle containing multiple small aggregates in an old ICR mouse treated for 36 days: $(\mathrm{N})$ immunostaining with polyclonal anti-Tg antibody and (O) PAS staining.

To test the likelihood that globules are processed upon stimulation, old mice were given a goitrogen treatment for different periods of time. After 12 days of goiter development, the thyroid still contained globules (not show). After 24 days, globules were found in hot follicles (Fig. 1L and M). After 36 days, they appeared as small and numerous fragments
(Fig. 1N and O). The proportion of 'hot' or 'cold' follicles, as well as of globules in each category (Fig. 2B) was not modified after 12 days of treatment, while 'hot' follicles became significantly more frequent than cold follicles after 24 days $(P<0.05)$. As previously shown $(9,13)$, the proportion of 'cold' follicles decreased with the duration of treatment to reach 
A

$\begin{array}{ll} & \square \text { "Hypofunctioning" follicles } \\ \text { HUMAN } & \square \text { "Hypofunctioning" follicles with globules }\end{array}$

".r. Active" follicles

$\nabla$ "Active" follicles with globules

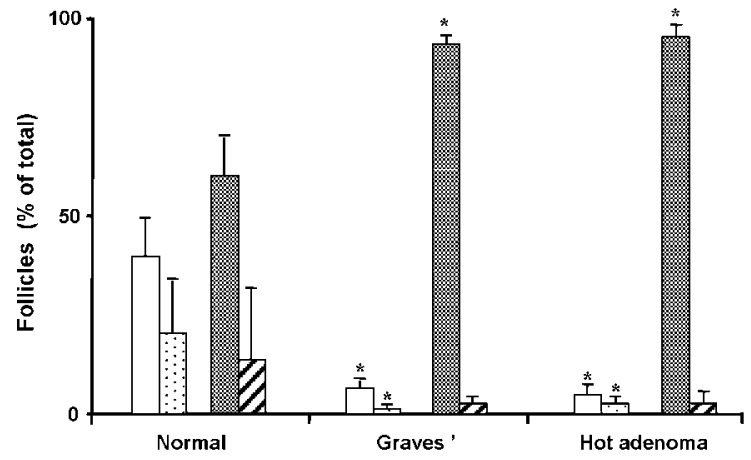

B

$\square$ "Cold" follicles

$\square$ "Cold" follicles with globules

"Hot" follicles

乙 "Hot" follicles with globules

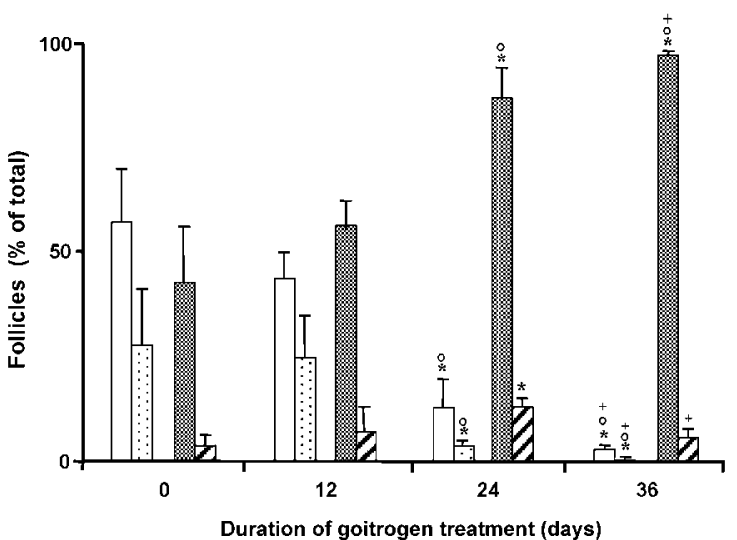

Figure 2 Quantification of globules in 'active' and 'hypofunctioning' follicles in normal and TSH-stimulated thyroids. Results are expressed in percentage of total follicles, i.e. 1000 follicles for human tissues or follicles from one thyroid lobe for old ICR mice; means \pm S.D., $n=5,0.5 \mu \mathrm{m}$ thick sections enlarged to $\times 400$. (A) Human thyroid tissues: normal, Graves' disease and 'hot' adenoma. ${ }^{*} P<0.05$ as compared with normal tissue. (B) Old ICR mice thyroids on goitrogen treatment for $0,12,24$, or 36 days. ${ }^{*} P<0.05$ vs day 0 , ${ }^{\circ} P<0.05$ vs day 12 of treatment, ${ }^{+} P<0.05$ vs day 24 of treatment.

$3 \pm 1 \%$ after 36 days $(P<0.001)$. The percentage of follicles containing globules (Table 1) significantly decreased at day 24 compared with control. At day 36 , globules were quite rare and a higher proportion of follicles contained more than one globule (Table 1). These results indicated that TSH stimulation of old mouse thyrocytes not only restores the activity of 'cold' follicles, but also induces the processing of $\mathrm{Tg}$ multimers that are progressively fragmented.

\section{Discussion}

This report shows that intrafollicular globules are frequently observed in normal human thyroids and in glands of old mice, where they are preferentially located in follicles with the morphological aspect of 'cold' follicles.

Although such globules are made of multimerized highly iodinated $\mathrm{Tg}$ (4-6), they are not recognized by polyclonal or monoclonal antibodies directed against specific Tg epitopes. This suggests that these epitopes, including a possible $\mathrm{T} 4$ residue at the $\mathrm{N}$-terminus of the peptide chain (B1 Mab), are either buried inside $\mathrm{Tg}$ aggregates, or covered by carbohydrate chains. Indeed, the structure of complex carbohydrate chains has noticeable effects on $\mathrm{Tg}$ immunoreactivity (16). In addition, terminal sialic acid of complex glycannic chains forms ionic bonds with basic amino acids of the protein backbone, which could account for the 
Table 1 Effect of goitrogen treatment on globule frequency and fragmentation. Percentage of total follicles with globules, and of follicles with globules in which more than one globule was observed. Old ICR mice were on goitrogen treatment for up to 36 days. $n=5$, except for the group treated for 36 days where $n=3$. Values are means \pm S.D.

\begin{tabular}{lcc}
\hline $\begin{array}{l}\text { Duration of } \\
\text { goitrogen } \\
\text { treatment } \\
\text { (days) }\end{array}$ & $\begin{array}{c}\text { Follicles with } \\
\text { globules } \\
\text { (\% of total) }\end{array}$ & $\begin{array}{c}\text { Follicles with more than } \\
\text { one globule } \\
\text { (\% of follicles with globules) }\end{array}$ \\
\hline 0 & $32 \pm 14$ & $40 \pm 9$ \\
12 & $32 \pm 13$ & $47 \pm 23$ \\
24 & $16 \pm 2^{*}, \circ$ & $51 \pm 11$ \\
36 & $6 \pm 2^{*}, \circ,+$ & $68 \pm 3^{*}$ \\
\hline
\end{tabular}

${ }^{*} P<0.05$ as compared with control. ${ }^{\circ} P<0.05$ as compared with day 12 of goitrogen treatment. ${ }^{+} P<0.05$ as compared with day 24 of goitrogen treatment.

decrease in antibody recognition (17). We believe that the epitope accessibility most likely depends on the tridimensional conformation of the cross-linked molecules, rather than on complex carbohydrate chain hindrance. Indeed, the treatment of paraffin sections with neuraminidase which breaks down the sialic acid-induced rigidity of the polysaccharide cover did not restore the antigenicity (not shown).

Covalent cross-links between $\mathrm{Tg}$ molecules has been suggested as a way to store $\mathrm{Tg}$ at a high concentration without increasing the osmolality $(4,5)$. The present study shows that globules are mostly observed in follicles with a low Tg turnover, 'hypofunctioning' follicles in the normal human thyroid and 'cold' follicles in aged mice. In the follicular lumen, Tg is heterogeneous in term of carbohydrate and iodine contents (18) and, notwithstanding its very high intrafollicular concentration, a selectivity in $\mathrm{Tg}$ uptake has been suggested (19). In hypoactive follicles, because of the endocytosis decline, Tg accumulates in the colloid (20). It has been suggested that the intermolecular cross-linking of lumenal hTg results from a combined mechanism of self-assisted and peroxidase-mediated disulfide bond formation (21). Our findings indicate that an increase in $\mathrm{Tg}$ concentration in the follicular lumen might facilitate $\mathrm{Tg}$ multimerization.

The original in vivo findings presented in this study have indicated that thyrocytes are able to metabolize the intrafollicular globules when stimulated by TSH. Three types of mechanism could account for globule dissolution: reduction of intermolecular covalent cross-links (disulfide or bi-tyrosine bonds) that maintain Tg compaction, oxidative attack of globule surface or limited extracellular proteolysis of peptide chains. First, isolated globules contain low amounts of protein-disulfide isomerase (PDI) (5) which could reduce intermolecular disulfide bridges. However, to catalyze this reaction, PDI requires a relatively reducing environment, when TSH conversely stimulates production of oxidizing equivalents (22). In addition, this hypothesis seems unlikely because PDI interaction with $\mathrm{Tg}$ requires acidic $\mathrm{pH}$ (23). Second, dispersion of Tg multimers could imply an oxidative breakage of intramolecular covalent bounds. Indeed, insoluble Tg has been shown in vitro to be degraded by a mild oxidation similar to that required for hormone synthesis $(6,24)$. This points to a potential role for the TPO-ThOX $-\mathrm{H}_{2} \mathrm{O}_{2}$ system. Indeed, TPO and ThOX immunoreactivity is low or absent, respectively, in 'hypofunctioning' follicles, but is gradually restored when activity is regained (12), which correlates with the variations in intrafollicular globule frequency. Upon TSH stimulation, one could propose that soluble $\mathrm{Tg}$ is primarily endocytosed which brings the residual globules into contact with the apical membrane where TPO and ThOX expression is induced. Third, several lysosomal enzymes are transported to the apical pole of isolated thyrocytes and could act extracellularly on the compact $\mathrm{Tg}$. Among proteases, the mature cathepsin $\mathrm{D}$ would be poorly active at the

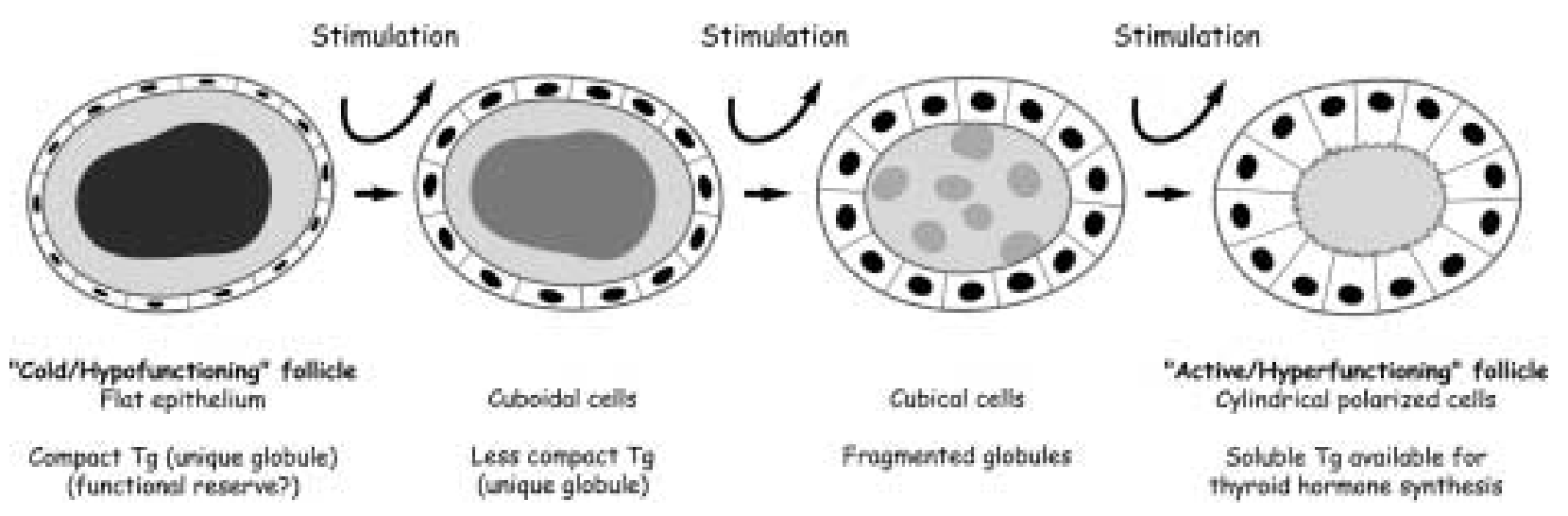

Figure 3 Processing of insoluble compact Tg globules in TSH-stimulated thyroids. Upon chronic TSH stimulation of old ICR mouse thyrocytes, when 'cold' follicles become active, soluble Tg is first endocytosed. Then, the intrafollicular globule is brought nearer to the apical pole of thyrocytes and gradually fragmented. Finally, solubilized globule content, either as intact Tg or as large Tg peptides, becomes suitable for thyroid hormone synthesis. 
neutral intrafollicular $\mathrm{pH}$ (25). Other candidates are cathepsins $\mathrm{B}$ and $\mathrm{K}$, two cysteine proteinases active at neutral $\mathrm{pH}$ that may contribute to the extracellular release of $\mathrm{T} 4(26,27)$. Interestingly, TSH stimulates their secretion from lysosomes in vitro $(28,29)$. Therefore, as far as their presence at the periphery of the follicular lumen is demonstrated in vivo, these enzymes, acting as endo- and exoproteases, might account for globule fragmentation upon TSH stimulation, i.e. in Graves' disease and autonomous adenomas in humans, and in iodoprive goiters in old mice. Endocytosis of the highly iodinated globule fragments, in which hormone content seems to be low (6), could occur before or after further TPO-induced modifications. Therefore, if one assumes that the physiological role of globules is to store iodinated prohormonal Tg, proteolysis would be subtle enough to keep intramolecular hormone synthesis possible in the solubilized fragments before endocytosis and hormone secretion.

In conclusion, the $\mathrm{Tg}$ globule is the morphological counterpart of multimerized $\mathrm{Tg}$ which serves to store the prohormone at a high concentration. When hypoactive 'cold' follicles become active upon TSHinduced chronic stimulation, Tg globules are processed to cover an increase in thyroid hormone production. In this paradigm, compact Tg globules are gradually fragmented and processed into fluid $\mathrm{Tg}$ which then becomes suitable for thyroid hormone synthesis (Fig. 3). This could help to maintain a thyroid hormone release adapted to increased physiological needs and to preserve the hormonal homeostasis.

\section{Acknowledgements}

The authors thank Dr J J M de Vijlder for providing monoclonal anti-Tg antibodies. This work was supported by the Fonds de la Recherche Scientifique Médicale (Belgium), M-F vdH is Research Associate of the National Fund for Scientific Research. Part of this work was presented at the 6th European Congress of Endocrinology, Lyon, France, April 2003.

\section{References}

1 Studer H, von Grünigen C, Haeberli A, Kohler H, Röthlisberger M \& Gerber H. Iodination of thyroglobulin molecules depends on their diffusion velocity in follicular colloid. Molecular and Cellular Endocrinology $1986 \mathbf{4 5} 91-103$.

2 Studer $\mathrm{H} \&$ Gerber $\mathrm{H}$. Intrathyroidal iodine. Heterogeneity in iodocompounds and kinetic compartmentalization. Trends in Endocrinology and Metabolism 19912 29-35.

3 Berg G \& Björkman U. The structure and properties of $27 \mathrm{~S}$ and larger iodoproteins in the thyroid gland. Biochimica et Biophysica Acta 1975405 11-22.

4 Herzog V, Berndorfer U \& Saber Y. Isolation of insoluble secretory product from bovine thyroid: extracellular storage of thyroglobulin in covalently cross-linked form. Journal of Cell Biology 1992 $1181071-1083$.

5 Berndorfer U, Wilms H \& Herzog V. Multimerization of thyroglobulin (TG) during extracellular storage: isolation of highly cross-linked TG from human thyroids. Journal of Clinical Endocrinology and Metabolism 199681 1918-1926.

6 Baudry N, Lejeune PJ, Delom F, Vinet L, Carayon P \& Mallet B. Role of multimerized porcine thyroglobulin in iodine storage. Biochemical and Biophysical Research Communications 1998242 292-296.

7 Denef JF, Maniratunga S, Gérard AC \& Many MC. What could mice tell us about goiter or other benign diseases? Experimental and Clinical Endocrinology and Diabetes 1996104 (Suppl 3) $48-51$.

8 Gerber H, Peter HJ, Bürgi E, Bigler S, Kaempf J \& Zbaeren J. Colloidal aggregates of insoluble inclusions in human goiters. Biochimie $199981441-445$.

9 Gérard AC, Xhenseval V, Colin IM, Many MC \& Denef JF. Evidence for co-ordinated changes between vascular endothelial growth factor and nitric oxide synthase III immunoreactivity, the functional status of the thyroid follicles, and the microvascular bed during chronic stimulation by low iodine and propylthiouracyl in old mice. European Journal of Endocrinology $2000 \mathbf{1 4 2}$ 651-660.

10 Denef JF, Haumont S, Cornette C \& Beckers C. Correlated functional and morphometric study of thyroid hyperplasia induced by iodine deficiency. Endocrinology 1981108 2352-2358.

11 Den Hartog MT, De Boer M, Veenboer JM \& De Vijlder JJM. Generation and characterization of monoclonal antibodies directed against non iodinated and iodinated thyroglobulin, among which are antibodies against hormonogenic sites. Endocrinology 1990127 3160-3165.

12 Gérard AC, Many MC, Daumerie C, Costagliola S, Miot F, DeVijlder JJM et al. Structural changes in the angiofollicular units between active and hypofunctioning follicles align with differences in the epithelial expression of newly discovered proteins involved in iodine transport and organification. Journal of Clinical Endocrinology and Metabolism 200287 1291-1299.

13 Studer H, Forster R, Conti A, Kohler H, Haeberli A \& Engler H. Transformation of normal follicles into thyrotropin-refractory 'cold' follicles in the aging mouse thyroid gland. Endocrinology $19781021576-1586$.

14 Tamura S \& Fujita H. Fine structural aspects on the 'cold' follicles in the aged mouse thyroid. Archivum Histologicum Japonicum 1981 44 177-188.

15 Mestdagh C, Many MC, Halpern S, Briançon C, Fragu P \& Denef JF. Correlated autoradiographic and ion-microscopic study of the role of iodine in the formation of 'cold' follicles in young and old mice. Cell and Tissue Research $1990 \mathbf{2 6 0} 449-457$.

16 Fenouillet E, Fayet G, Hovsepian S, Bahraoui EM \& Ronin C. Immunochemical evidence for a role of complex carbohydrate chains in thyroglobulin antigenicity. Journal of Biological Chemistry 1986261 15153-15158.

17 Montreuil J. Spatial conformation of glycans and glycoproteins. Biology of the Cell 198451 115-132.

18 Dunn TJ \& Ray S. Variations in the structure of thyroglobulins from normal and goitrous human thyroids. Journal of Clinical Endocrinology and Metabolism 197847 861-869.

19 van den Hove MF, Couvreur M, de Visscher M \& Salvatore G. A new mechanism for the reabsorption of thyroid iodoproteins: selective fluid pinocytosis. European Journal of Biochemistry 1982 $122415-422$.

20 Gerber H, Peter HJ \& Studer H. Age-related failure of endocytosis may be the pathogenic mechanism responsible for 'cold' follicle formation in the aging mouse thyroid. Endocrinology $1987 \mathbf{1 2 0}$ $1758-1764$.

21 Klein M, Gestmann I, Berndorfer U, Schmitz A \& Herzog V. The thioredoxin boxes of thyroglobulin: possible implications for intermolecular disulfide bond formation in the follicle lumen. Biological Chemistry 2000381 593-601.

22 Corvilain B, Laurent E, Lecomte M, Vansande J \& Dumont JE. Role of the cyclic adenosine $3^{\prime}, 5^{\prime}$-monophosphate and the phosphatidylinositol- $\mathrm{Ca}^{2+}$ cascades in mediating the effects of thyrotropin and iodide on hormone synthesis and secretion in human thyroid 
slices. Journal of Clinical Endocrinology and Metabolism 199479 152-159.

23 Mezghrani A, Courageot J, Mani JC, Pugniere M, Bastiani P \& Miquelis R. Protein-disulfide isomerase (PDI) in FRTL5 cells. pHdependent thyroglobulin/PDI interactions determine a novel PDI function in the post-endoplasmic reticulum of thyrocytes. Journal of Biological Chemistry 2000275 1920-1929.

24 Delom F, Lejeune PJ, Vinet L, Carayon P \& Mallet B. Involvement of oxidative reactions and extracellular protein chaperones in the rescue of misassembled thyroglobulin in the follicular lumen. Biochemical and Biophysical Research Communications 1999255 438-443.

25 Lemansky P, Brix K \& Herzog V. Iodination of mature cathepsin D in thyrocytes as an indicator for its transport to the cell surface. European Journal of Cell Biology 1998 76 53-62.

26 Brix K, Lemansky P \& Herzog V. Evidence for extracellularly acting cathepsins mediating thyroid hormone liberation in thyroid epithelial cells. Endocrinology 1996137 1963-1974.
27 Tepel C, Brömmer D, Herzog V \& Brix K. Cathepsin K in thyroid epithelial cells: sequence, localization and possible function in extracellular proteolysis of thyroglobulin. Journal of Cell Science $20001134487-4498$.

28 Brix K, Linke M, Tepel C \& Herzog V. Cysteine proteinase mediates extracellular prohormone processing in the thyroid. Biological Chemistry 2001382 717-725.

29 Linke M, Herzog V \& Brix K. Trafficking of lysosomal cathepsin Bgreen fluorescent protein to the surface of thyroid epithelial cells involves the endosomal/lysosomal compartment. Journal of Cell Science $20021154877-4889$.

Received 1 August 2003

Accepted 7 October 2003 